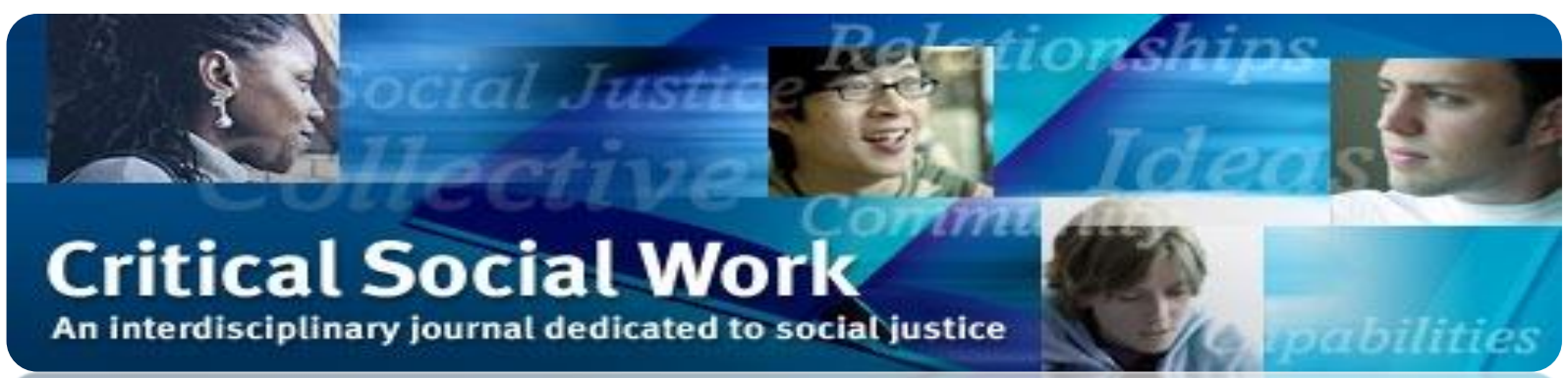

Critical Social Work

School of Social Work

University of Windsor

167 Ferry Street

Windsor, Ontario N9A 0C5

Email: cswedit@uwindsor.ca

Publication details, including instructions for authors and subscription information can be found at: http://uwindsor.ca/criticalsocialwork

Link to article:

http://www1.uwindsor.ca/criticalsocialwork/BookReviewParadoxesSWPractice

Critical Social Work, 2017 Vol. 18, No. 1 


\title{
Book Review: Paradoxes in Social Work Practice: Mitigating Ethical Trespass
}

\section{Critical Social Work 18(1)}

Dorothee Hölscher

\author{
University of KwaZulu Natal, South Africa
}

\begin{abstract}
Author: Weinberg, Merlinda
Published: 2016

Published By: Routledge

Hardcover ISBN 978-1-4724-309-71

Number of Pages: 179
\end{abstract}

Name of Book: Paradoxes in Social Work: Mitigating Ethical Trespass

Merlinda Weinberg's Paradoxes in Social Work: Mitigating Ethical Trespass narrates a compelling study of the experiences of five front line social workers, who through their work, found themselves entangled in a complex web of injustice that pre-structured, and sometimes predetermined, the life courses of young mothers and fathers in Ontario, Canada. The book enriches the existing literature on social work ethics and is thus a worthwhile read. The monograph is based upon Weinberg's analysis of 28 qualitative interviews she held with these practitioners over a period of two years. Her analysis begins from the assumption that there are six fundamental paradoxes - including among others, the well-debated paradox of care versus discipline. These set social work practice up in such a way that ethical trespass becomes unavoidable. Citing Hannah Arendt (1958) and Melissa Orlie (1997), Weinberg defines ethical trespass as "the harmful effects ... that inevitably follow not from our intentions and malevolence but from our participation in social processes and identities" (Weinberg, 2016, p. 17). To explore her participants' experiences and handling of these paradoxes and the trespasses that followed, Weinberg (2016, p. 7) adopts "a critical approach that employs both structural and post-structural theorising". This approach enables her, firstly, to illuminate the discursive traditions and interpretive leanings adopted by her research participants in the narration of their practice experiences, challenges and dilemmas. Secondly, it facilitates an in-depth discussion of the way these discourses interacted, sometimes complementing and at others contradicting one another in her participants' interpretation of their work. In her final analytic step, Weinberg demonstrates the ways in which these interpretations led to particular practice choices. Weinberg (2016, p. 1) wants to better understand "how, if at all, it is possible to practice in an ethical fashion, given the contradictions in the ... profession of social work". The outcome of her 
explorations is "a tale" of Weinberg's "own anguish about the current state of social services", her "anxiety about the possibilities of anti-oppressive applications in the field", and her "passionate hope in the potential to edge towards more ethical practice" (Weinberg, 2016, p. 26).

Living and working in South Africa, I read this book in the context of a country that is battling to shake off the effects of over 350 years of colonialism and apartheid rule at a time when classic liberalism has experienced more than 40 years of global renaissance. Yet in spite of all the undeniable, substantive differences that distinguish the lives of citizens of the global South from those of the global North, the case studies described and discussed across the book reminded me of many scenarios I have encountered over my years of working, studying, and supervising social work students in South Africa. Weinberg's often troubling accounts even reminded me of Emmeline Pankhurst's (2015 [1914], pp. 25-26) vivid description of the treatment of young unmarried mothers in the Manchester workhouse of the 1890s. Of course, societies of the global North have come a long way in the 120 years that passed since. Nonetheless, my point is that all differences across space and time notwithstanding, Paradoxes in Social Work amply evidences a persistence in the workings of discourses and practices, in the structures and dynamics of injustice that are deeply concerning. In fact, as indicated by the term ethical trespass, Weinberg painstakingly evidences how, and explains why, it is impossible for practitioners not to become implicated in prevailing regimes of injustice.

For all the complexities of its contents, the book follows a simple structure. Chapter 1 outlines key concepts, provides a summative overview of the study, and an overview of chapters. Chapters 2 to 5 are structured around a broad selection of case studies from Weinberg's research participants. In Chapter 2, Weinberg uses such examples to demonstrate how three contemporary discourses on young single mothers - the "liberal", the "reactionary", and the "revisionist or oppositional discourse" (Weinberg, 2016, pp. 12-14) - operated to create particular ethical dilemmas in her participants' work, thereby drawing them towards particular, preferred, kinds of responses. Chapter 3 focuses on "micro relations", and considers how "power, judgement, and emotions" (Weinberg, 2016, p. 63) were enacted and interacted within the relationships between her participants and their respective service users. This enables Weinberg to demonstrate how well-meaning people, through well-intentioned social work interventions, can become entangled unwittingly, yet actively participate in the day-to-day recreation of oppressive race, class, and gender relations in modern, constitutionally democratic societies. In Chapter 4, Weinberg turns her attention to "macro relations" (Weinberg, 2016, p. 93) and considers how four decades of neoliberalism have shaped the economic, social, political, cultural, and ideological contexts of Canadian welfare services. Again with great attention to detail and grounding her assertions in the case studies provided by her participants, Weinberg (2016, p. 118) finds that,

The location of workers in organisations, the complexity of the social service system, the political and economic environment with its politics of scarcity, the move towards a more market-driven system, and the emphasis on individualism and governmentality all significantly impacted on a workers' abilities to act in ways that they perceived as ethical. Those factors are the very material the resulted in the inevitability of ethical trespass (highlights in original). 
Precisely this dynamic is what at once implicates and renders practitioners victims of broader structures and processes of injustice. Importantly, this observation provides the springboard for Weinberg's subsequent exploration of how social workers might resist - not just for the sake of their service users, but also for themselves, and for the benefit of the kinds of service user-service provider relationships that might transpire as a result. Resistance is an important theme in Chapter 5: Mitigating Trespass. Here, Weinberg invokes Sandra Harding's image of the "responsible traitor" (Heldke, 1998, p. 90) and, drawing on her participants' stories one more time, proposes ways of problematizing helping relationships, of responding to difference, of linking reason, affect and empathy, and of mitigating, resisting, and working strategically to change unjust structures and processes in contemporary welfare practice.

Against the background of her findings, Weinberg (2016, p. 166) concludes that there is no reason to "concede defeat and give up", even in the face of what might seem to be overwhelming structural odds against ethical, justice-oriented, practice. Instead, she meticulously demonstrates that critical social work, that ethical practice - one that considers social work's entanglement in prevailing neoliberal ideologies, in limiting organisational and professional hierarchies, and in the continuous recreation of oppressive gender, class, and race relations remain desirable, necessary, and possible. Staying clear of offering false hope about what radical and anti-oppressive social work interventions might be able to accomplish at the present conjuncture, Weinberg nonetheless maintains that it is worthwhile, and rewarding, to continue chipping away at social work's project of a better, that is a more just, world in which all people can flourish.

\section{Book Review Author Biography}

Dorothee Hölscher is a lecturer and acting academic leader of social work at the University of Kwa-Zulu Natal. She serves as secretary and as the convenor of the Ethics Working Group of the Association of Schools of Social Work in Africa (ASSWA). Her areas of interest include applied ethics in social work, practice with cross-border migrants, and antioppressive social work theory and practice. Her recent publications also include: The political is personal: On being, knowing, and doing something about social justice', in R. Hugman and J. Carter, J. (Eds.) Rethinking values and ethics in social work, Houndmills, Basingstoke, Hampshire, New York: Palgrave Macmillan: 97-112. 


\section{References}

Arendt, H. (1958). The human condition. Chicago, IL: University of Chicago.

Heldke, L. (1998). On becoming a responsible traitor. A primer. In B.-A. Bar On and A.

Ferguson (Eds.), Daring to do good. Essay in feminist ethico-politics (pp. 87-99). New York, NY: Routledge.

Orlie, M. A. (1997). Living ethically. Acting politically. Ithaca, NY: Cornell University Press. Pankhurst, E. (2015 [1914]). My own story. London, ENG: Vintage. 